\title{
Cardiovascular safety of exenatide BID: an integrated analysis from controlled clinical trials in participants with type 2 diabetes
}

\author{
Robert Ratner ${ }^{1}$, Jenny Han², Dawn Nicewarner ${ }^{2}$, Irina Yushmanova ${ }^{2}$, Byron J Hoogwerf ${ }^{3}$, Larry Shen ${ }^{2 *}$
}

\begin{abstract}
It is important for patients that treatments for diabetes not increase cardiovascular (CV) risk. The objective of this analysis was to examine retrospectively the CV safety of exenatide BID, a GLP-1 receptor agonist approved for treating hyperglycemia in patients with type 2 diabetes not adequately controlled with diet and exercise. Individual participant data was pooled to assess the relative risk (RR) of CV events with exenatide BID versus a pooled comparator (PC) group treated with either placebo or insulin from 12 controlled, randomized, clinical trials ranging from 12-52 weeks. Mean baseline values for $\mathrm{HbA}_{1 \mathrm{c}}(8.33-8.38 \%), \mathrm{BMI}\left(31.3-31.5 \mathrm{~kg} / \mathrm{m}^{2}\right)$, and duration of diabetes (8 y) were similar between groups. Trials included patients with histories of microvascular and/or macrovascular disease. Customized primary major adverse CV events (MACE) included stroke, myocardial infarction, cardiac mortality, acute coronary syndrome, and revascularization procedures. The Primary MACE RR $(0.7 ; 95 \% \mathrm{Cl} 0.38,1.31)$, calculated by the Mantel-Haenszel method (stratified by study), suggested that exenatide use (vs. PC) did not increase CV risk; this result was consistent across multiple analytic methods. Because the trials were not designed to assess CV outcomes, events were identified retrospectively from a list of preferred terms by physicians blinded to treatment. Other limitations included the low number of CV events, the short duration of trials $(\leq 1 \mathrm{y})$, and a single active comparator (insulin). The results of these analyses are consistent with those of a recent retrospective analysis of a large insurance database that found that patients treated with exenatide twice daily were less likely to have a CV event than were patients treated with other glucose-lowering therapies.

Keywords: GLP-1 receptor agonist, diabetes, cardiovascular safety
\end{abstract}

\section{Background}

Despite the numerous advancements in glucose-lowering medications in recent years, the incidence of cardiovascular $(\mathrm{CV})$ morbidity and mortality in patients with type 2 diabetes has not consistently decreased [1]. In 2007, a controversial, widely publicized meta-analysis of 42 trials suggested that rosiglitazone, a thiazolidinedione (TZD), was associated with increased risk of myocardial infarction (MI) and death due to CV events [2-6]. At that time, a joint advisory committee meeting concluded that rosiglitazone increased myocardial ischemia and the FDA added a black box warning to the rosiglitazone label $[2,7]$. Although a non-inferiority CV outcomes trial, RECORD concluded that rosiglitazone did not

\footnotetext{
* Correspondence: Ishen@amylin.com

${ }^{2}$ Amylin Pharmaceuticals, Inc., San Diego, CA, USA

Full list of author information is available at the end of the article
}

increase $\mathrm{CV}$ morbidity or mortality compared with other glucose-lowering medications [8]; the open-label and unblinded design of RECORD prompted some to question the quality of the data [7]. Following updated meta-analyses and recent congressional inquiry, concerns arose again about the CV safety of rosiglitazone [9-12]. Recently, an advisory committee meeting (July 2010) concluded that rosiglitazone significantly increased CV risk [7].

The risk-to-benefit profile of medications may begin to take on greater importance for future approvals of new drugs $[13,14]$. Exenatide twice daily (exenatide BID) was the first GLP-1 receptor agonist approved for treatment of hyperglycemia in patients with type 2 diabetes not adequately controlled with diet and exercise, sulfonylurea (SFU), TZD, or metformin (MET; alone, or with an SFU, or TZD). In addition to glycemic control and a low risk of hypoglycemia, exenatide may favorably affect

\section{C) Biomed Central}


several CV risk factors, such as blood pressure, lipid profiles, and body weight [15-17]. Because the incidence of $\mathrm{CV}$ events was low in each of the clinical trials, we undertook this pooled analysis to provide an integrated assessment of the CV safety data from 12 studies with exenatide BID.

\section{Methods}

\section{Study Selection}

For each clinical trial, a protocol was approved by an institutional review board, in accordance with the principles described in the Declaration of Helsinki (World Medical Association 1997). Each of the trials included in this analysis was conducted by Amylin Pharmaceuticals, Inc. and Eli Lilly and Company. Complete efficacy and safety data for these trials have been reported previously [18-29]. Randomized, controlled trials (8 blinded, 4 open-label) that were completed by September 30, 2008 and of at least 12 weeks in duration, that were included in this analysis were designed to compare the efficacy and tolerability of exenatide BID to placebo or insulin (Table 1). They were either placebo-controlled or activecontrolled studies where insulin served as the comparator. The studies included in this analysis were not designed to assess $\mathrm{CV}$ events and events were not prospectively adjudicated.

\section{Analysis population}

The current analyses included patients from the intentto-treat populations (i.e., patients who received at least 1 dose of randomized study medication) of each study
(Table 1). Patients in all studies had type 2 diabetes and were treated continuously with exenatide and MET, SFU, or TZD alone or in combination. All patients were 18 to 75 years-of-age, had a $\mathrm{HbA}_{1 \mathrm{c}} \leq 11.0 \%$, a body mass index (BMI) of 25 to $45 \mathrm{~kg} / \mathrm{m}^{2}$, and a history of stable body weight ( $\leq 10 \%$ change) for at least 3 months. Patients were excluded if they had used weight loss drugs or had evidence of a significant medical condition. Investigators were asked to exclude patients with evidence of active cardiac disease within 1 year prior to the study, i.e., MI, clinically significant arrhythmia, unstable angina, moderate to severe congestive heart failure, coronary artery bypass surgery, or angioplasty. Patients with a $>1$ year history of MI, transient ischemic attack or large vessel disease or with a history of microvascular disease were eligible for enrollment. All patients provided written informed consent before participation.

\section{Outcomes}

Events were identified by preferred terms according to the Medical Dictionary for Regulatory Activities (MedDRA 11.0). A team of physicians, blinded to treatment, independently reviewed the list of preferred terms prior to the analyses to focus on the terms most likely to represent true events of interest, regardless of occurrence. Blinded adjudication of the CV events was not pre-specified in the study protocols; therefore, events were identified retrospectively using the prespecified list of preferred terms independent of whether or not the events had occurred. At the time of the occurrence during the original trial, the events

Table 1 Summary of controlled studies included in CV analysis

\begin{tabular}{|c|c|c|c|c|c|c|c|}
\hline & & \multirow[b]{2}{*}{ Diabetes Management } & \multirow[b]{2}{*}{ Duration* (Weeks) } & \multicolumn{2}{|c|}{ Exenatide† } & \multicolumn{2}{|c|}{ Placebo or Comparator } \\
\hline \multicolumn{2}{|c|}{ Study/Registry Number } & & & ITT (N) & Exposure (SY) & ITT (N) & Exposure (SY) \\
\hline DeFronzo et al, $2005^{18}$ & NCT00039013 & Met & 30 & 223 & 113.8 & 113 & 57.8 \\
\hline Buse et al, $2004^{20}$ & NCT00039026 & SFU & 30 & 254 & 123.2 & 123 & 55.1 \\
\hline Kendall et al, $2005^{19}$ & NCT00035984 & Met + SFU & 30 & 486 & 254.9 & 247 & 122.2 \\
\hline Zinman et al, $2007^{24}$ & NCT00099320 & $\mathrm{TZD} \pm$ Met & 16 & 121 & 31.7 & 112 & 32.3 \\
\hline Kadowaki et al, $2008^{27}$ & NCT00382239 & $\mathrm{SFU} \pm$ Met & 12 & 111 & 23.9 & 40 & 9.2 \\
\hline Gao, et al, $2009^{26}$ & NCT00324363 & Met \pm SFU & 16 & 234 & 65.5 & 233 & 67.3 \\
\hline Moretto et al, $2008^{28}$ & NCT00381342 & $D+E$ & 24 & 155 & 65.2 & 77 & 33.1 \\
\hline Gill et al, $2010^{29}$ & NCT00516074 & Met and/or TZD & 12 & 28 & 5.8 & 26 & 5.7 \\
\hline Heine et al, $2005^{22}$ & NCT00082381 & Met + SFU & 26 & 282 & 122.5 & 267 & 124.6 \\
\hline Nauck et al, $2007^{23}$ & NCT00082407 & Met + SFU & 52 & 253 & 220.1 & 248 & 228.6 \\
\hline Davis et al, $2007^{25}$ & NCT00099333 & SFU or Meg and/or Met & 16 & 33 & 7.7 & 16 & 5.2 \\
\hline Barnett et al, $2007^{21}$ & NCT00099619 & Met or SFU & $16 \neq$ & 136 & 37.3 & 127 & 38.9 \\
\hline Totals & & - & - & 2,316 & $1,071.6$ & 1,629 & 779.9 \\
\hline
\end{tabular}

$\mathrm{D}+\mathrm{E}=$ diet and exercise therapy; ITT = Intent-to-Treat Population; Meg = meglitinide; Met = metformin; OAD = oral antidiabetic medications; SFU = sulfonylurea; TZD = thiazolidinedione.

*Duration of treatment with randomized study medication.

${ }^{+}$Includes treatment with exenatide $2.5 \mathrm{mcg}$ or $5 \mathrm{mcg}$ BID for duration of study, or 4 weeks of exenatide 5 mcg BID followed by exenatide 10 mcg BID for remainder of study.

${ }^{\ddagger}$ NCT00099619 had a crossover design, with 16 weeks per period (exenatide or insulin glargine). 
were closely reviewed in accordance with normal clinical trial monitoring and follow-up of adverse events, laboratory evaluations, physical examinations, vital signs measurements, with particular attention to serious adverse events.

All data for patients who died were examined to ascertain if the underlying cause was $\mathrm{CV}$ in nature based on the preferred term provided and the cases were reviewed in detail. "Sudden deaths" were adjudicated as CV events, in conformance with most large CV outcomes trials [30-35]. The final list of terms was concordant with the FDA list presented at the advisory committee meeting in April 2009 for other antidiabetic agents [36].

\section{Primary Outcome}

The primary outcome was Primary Major Adverse CV Events (MACE); per FDA guidance, it included terms reflective of $\mathrm{CV}$ mortality, stroke, myocardial infarction, acute coronary syndrome, and revascularization procedures.

\section{Secondary Outcome}

The secondary CV endpoint included all relevant CV adverse events. This expanded endpoint comprised all terms of the Primary MACE endpoint plus terms for arrhythmia, heart failure (with or without hospitalization), and mechanical-related events. Mechanical-related events were aortic valve disease, aortic valve stenosis, cardiac failure congestive, cardiomegaly, CV disorder, heart valve incompetence, left atrial dilatation, mitral valve incompetence, and tricuspid valve incompetence. Heart failure and mechanical-related adverse events were included in an effort to encompass as many potentially important CV-related events as possible.

\section{Analysis}

A meta-analysis was performed on 12 completed longerterm (3- to 12-month), randomized, placebo- or insulin comparator-controlled trials of exenatide BID, in accordance with the FDA guidelines [37]. Data from approximately 4,000 patients with type 2 diabetes and an average exposure of 24 weeks were included [18-29]. Pooled data from placebo- and insulin-treated patients were compared with pooled data from exenatide-treated patients. The exenatide cohort included participants randomized to receive exenatide BID $2.5 \mathrm{mcg}(\mathrm{n}=37)$, $5 \mathrm{mcg}(\mathrm{n}=594)$, or $10 \mathrm{mcg}(\mathrm{n}=1,685)$. Because of the low number of $\mathrm{CV}$ events, the 3 exenatide dose groups were combined.

For the primary analysis, the Relative Risk (RR) of an incident CV event and the corresponding 95\% confidence interval (CI) were calculated using Mantel-Haenszel method stratified by study. In order to demonstrate robustness, the RR and its $95 \% \mathrm{CI}$ were calculated using the following additional methods: pooled RR (without stratification by study and with common continuity correction [i.e., adding 0.5 to all cells if one of the treatment groups had no events]) and Shuster's RR [38] (weights all trials equally and included studies with no events). The Hazard Ratio (HR) was calculated using 2 methods: 1 ) the Cox proportional hazard model (time to first event) with adjustment for study, and 2) the Andersen-Gill model (recurrent events) with adjustment for study. Ninety-five percent CIs for the RR and HR were provided at a 2-sided significance level of 0.05. Weighted KaplanMeier survival curves were generated to show the time to first event and the proportion of patients who were riskfree over time [39]. The time to event was calculated from the first randomized dose to the time of the first cardiac event. Exposure Adjusted Incidence Rate (EAIR) and its 95\% CI were calculated using the Exact method [40]. The RR and its 95\% CI based on EAIR and event rate were provided [41].

Additional subgroup analyses by age (<65 vs. $\geq 65)$, BMI ( $<30$ vs. $\geq 30$ ), and renal function (normal, mild impairment, and moderate impairment) were provided to assess the effects of these baseline characteristics. SAS 9.2 ${ }^{\circledR}$ (Statistical Analysis Software, Cary, NC, USA) was used for all analyses.

\section{Results}

The data included in these analyses represented 1,072 patient-years (PY) exposure with exenatide BID $(\mathrm{N}=$ $2,316)$ and $780 \mathrm{PY}$ exposure with comparators (placebo, $\mathrm{n}=971$; insulin, $\mathrm{n}=658$ ). Demographic and baseline characteristics were similar between treatment groups (Table 2). Participants had similar mean baseline values for $\mathrm{HbA}_{1 \mathrm{c}}(8.33 \%-8.38 \%)$, BMI (31.3-31.5 $\left.\mathrm{kg} / \mathrm{m}^{2}\right)$, and duration of diabetes (8 years). Of note, the mean systolic blood pressures at baseline for both cohorts were $131 \pm$ $4 \mathrm{~mm} \mathrm{Hg}$ and $132 \pm 5 \mathrm{~mm} \mathrm{Hg}$ for the exenatide and the pooled comparator cohorts, respectively. Some patients had a past history of CV disease (including multiple events) and/or microvascular disease (including multiple conditions). From baseline to endpoint, heart rate changes were $+0.5 \pm 9.8$ beats per minute $(\mathrm{bpm})$ for exenatide and $+0.1 \pm 9.2 \mathrm{bpm}$ for the pooled comparators (mean $\pm \mathrm{SD}$ ).

Incidence rates of Primary MACE were similar for $5 \mathrm{mcg}(0.9 \%)$ and $10 \mathrm{mcg}(1.1 \%)$ exenatide dose groups, and no events were observed in the $2.5 \mathrm{mcg}$ group. Therefore, data from all exenatide doses $(2.5 \mathrm{mcg}$, $5 \mathrm{mcg}, 10 \mathrm{mcg}$ ) were pooled in the analyses. The EAIR for exenatide treatment group was 18.73 per 1,000 patient-years versus 23.17 per 1,000 patient-years for the pooled comparator group (Table 3). Overall, 26 participants experienced serious adverse CV events: 15 (0.6\%) 
Table 2 Baseline characteristics and demographics

\begin{tabular}{|c|c|c|}
\hline Baseline Characteristics & $\begin{array}{c}\text { Exenatide }(\mathrm{N}= \\
2,316)\end{array}$ & $\begin{array}{l}\text { Pooled Comparator } \\
\qquad(\mathrm{N}=1,629)\end{array}$ \\
\hline Gender, M/F (\%) & $56 / 44$ & $53 / 47$ \\
\hline \multicolumn{3}{|l|}{ Race (\%) } \\
\hline Caucasian & 64 & 65 \\
\hline Black & 6 & 4 \\
\hline Hispanic & 11 & 10 \\
\hline Asian & 19 & 20 \\
\hline Other & 1 & 1 \\
\hline Age (years) & $56 \pm 10$ & $56 \pm 10$ \\
\hline$\geq 65$ years $(\%)$ & 21 & 20 \\
\hline $\begin{array}{l}\text { Duration of Diabetes } \\
\text { (years) }\end{array}$ & $8 \pm 6$ & $8 \pm 6$ \\
\hline$\geq 10$ years $(\%)$ & 32 & 35 \\
\hline Weight (kg) & $89.1 \pm 20.3$ & $87.8 \pm 19.8$ \\
\hline $\begin{array}{l}\text { Body Mass Index (BMI [kg/ } \\
\left.\mathrm{m}^{2}\right] \text { ) }\end{array}$ & $31.5 \pm 5.6$ & $31.3 \pm 5.4$ \\
\hline $\mathrm{BMI}<30$ kg/m² (\%) & 44 & 45 \\
\hline $\mathrm{BMI} \geq 30 \mathrm{~kg} / \mathrm{m}^{2}(\%)$ & 56 & 55 \\
\hline $\mathrm{HbA}_{1 \mathrm{c}}(\%)$ & $8.33 \pm 1.06$ & $8.38 \pm 1.07$ \\
\hline $\begin{array}{l}\text { Systolic Blood Pressure } \\
\text { (SBP [mm Hg]) }\end{array}$ & $131 \pm 4$ & $132 \pm 5$ \\
\hline $\begin{array}{l}\text { Diastolic Blood Pressure } \\
\text { (DBP [mm Hg]) }\end{array}$ & $79 \pm 2$ & $79 \pm 1$ \\
\hline $\begin{array}{l}\text { Heart Rate (beats per } \\
\text { minute) }\end{array}$ & $75 \pm 9$ & $75 \pm 9$ \\
\hline \multicolumn{3}{|l|}{$\begin{array}{l}\text { Renal Function } \\
\text { Impairment* }(\%)\end{array}$} \\
\hline None & 86 & 86 \\
\hline Mild & 13 & 14 \\
\hline Moderate & 1 & 1 \\
\hline
\end{tabular}

Data are mean \pm SD unless otherwise noted. Percentages may not add to 100 due to rounding.

* Renal function is defined based on creatinine clearance $(\mathrm{CrCl})$ as calculated by the Cockcroft-Gault equation: normal, $\mathrm{CrCl}>80 \mathrm{~mL} / \mathrm{min}$; mild impairment, $\mathrm{CrCl}>50-80 \mathrm{~mL} / \mathrm{min}$; moderate impairment, $\mathrm{CrCl}>30-50 \mathrm{~mL} / \mathrm{min}$. in the exenatide group and $11(0.7 \%)$ in the pooled comparator group (data not shown). Four fatal CV events occurred: 2 in the exenatide group (MI, atrial fibrillation) and 2 in the comparator group (MI, cerebrovascular accident).

The point estimates for Primary MACE and Secondary $\mathrm{CV}$ endpoints between exenatide BID and the pooled comparator were both 0.7 (the upper limits of the 95\% CIs were 1.3 and 1.0, respectively), in favor of exenatide (Figure 1). These results suggest that exenatide did not increase the CV risk. For the individual studies, the point estimates for RR were $<1.0$ (favoring exenatide) for 10 of 12 long-term controlled studies (Figure 2). In addition, the RRs and 95\% CIs for the Primary MACE were consistent across multiple methods of analysis (including sensitivity analyses of RR based on incidence and RR based on EAIR event rate), with point estimates ranging from 0.5 to 0.8 , and the upper limit of the $95 \%$ CIs ranging from 1.3 to 1.5 (Figure 3 ). Similar point estimates were observed for the broader secondary $\mathrm{CV}$ endpoint; however, the upper limit of the $95 \%$ CI was $<1.3$ for all methods (Figure 3). A weighted KaplanMeier plot shows that a significantly higher percentage of exenatide-treated patients than pooled comparatortreated patients were free of a primary MACE event over 1 year $(P<0.0001$; Figure 4$)$.

\section{Discussion}

Assessing the CV Risk of Glucose-Lowering Therapies

One of the strengths of this meta-analysis is the use of individual participant data from each of the trials, in contrast with a typical meta-analysis in which summary statistics for individual studies are used. Another strength was the use multiple methods of analysis, some of which allowed for the inclusion of studies with zero

Table 3 Incidence rates and exposure-adjusted incidence rates for primary MACE and secondary CV endpoints

\begin{tabular}{|c|c|c|c|c|}
\hline & \multicolumn{2}{|c|}{ Primary MACE Endpoint } & \multicolumn{2}{|c|}{ Secondary MACE Endpoint } \\
\hline & $\begin{array}{l}\text { Exenatide } \\
(\mathrm{N}=2,316)\end{array}$ & $\begin{array}{l}\text { Pooled Comparator } \\
\qquad(N=1,629)\end{array}$ & $\begin{array}{l}\text { Exenatide } \\
(\mathrm{N}=2,316)\end{array}$ & $\begin{array}{l}\text { Pooled Comparator } \\
\qquad(\mathrm{N}=1,629)\end{array}$ \\
\hline \multicolumn{5}{|l|}{ Primary Analyses } \\
\hline Incidence (n) & 20 & 18 & 46 & 42 \\
\hline Incidence (n/N) & 0.009 & 0.011 & 0.020 & 0.026 \\
\hline RR $(95 \% \mathrm{Cl})$ & \multicolumn{2}{|c|}{$0.70(0.38,1.31)$} & \multicolumn{2}{|c|}{$0.69(0.46,1.03)$} \\
\hline \multicolumn{5}{|l|}{ Secondary Analysis } \\
\hline EAIR (per 1,000 years) & 18.73 & 23.17 & 43.37 & 54.37 \\
\hline RR $(95 \%$ Cl) & \multicolumn{2}{|c|}{$0.81(0.43,1.53)$} & \multicolumn{2}{|c|}{$0.80(0.53,1.21)$} \\
\hline Event Rate (per 1,000 years) & 22.40 & 28.21 & 54.13 & 66.67 \\
\hline RR $(95 \%$ Cl) & \multicolumn{2}{|c|}{$0.79(0.45,1.42)$} & \multicolumn{2}{|c|}{$0.81(0.56,1.18)$} \\
\hline
\end{tabular}

$\mathrm{Cl}$ = confidence interval; $\mathrm{CV}=$ cardiovascular; $\mathrm{EAIR}=$ exposure-adjusted incidence rate; $\mathrm{MACE}=$ major adverse cardiovascular events; $\mathrm{RR}=$ risk ratio. RR for the incidence was calculated using the Mantel-Haenszel estimate with study as a stratification factor.

EAIR and event rate were calculated based on the Exact method, with corresponding RR calculated using the log-normal approximation. 


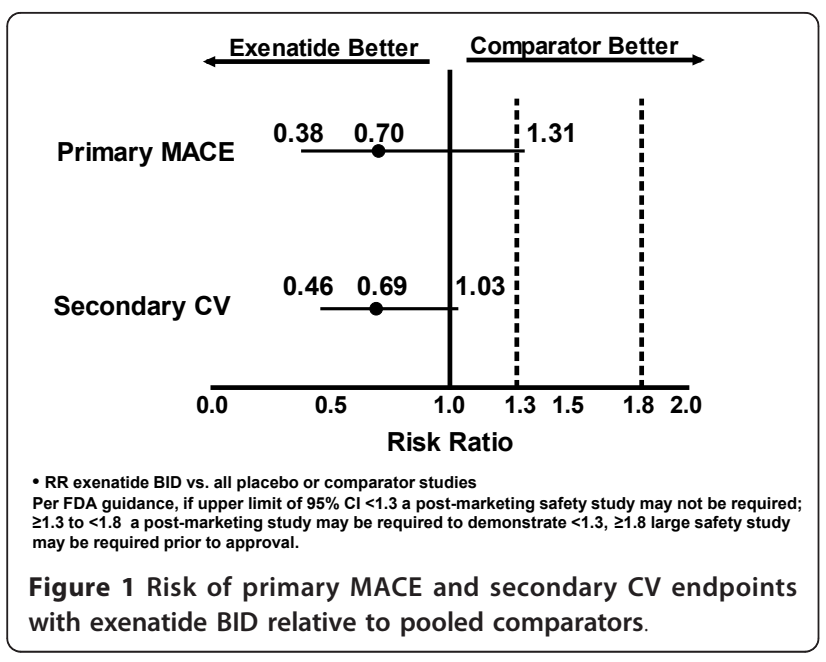

$\mathrm{CV}$ event rates. The results of this meta-analysis provide a preliminary assessment of the $\mathrm{CV}$ risk associated with exenatide treatment across trials used for registration. Because these findings are not conclusive, a prospective, adequately-powered, adjudicated, CV outcome study (NCT01144338) of the investigational once-weekly formulation of exenatide was initiated.
Applying the FDA guidance on how to assess CV safety in the development of treatments for type 2 diabetes to this analysis, the HR point estimates were both $<1$ for the Primary MACE and Secondary CV endpoints resulting from the lower observed incidence of $\mathrm{CV}$ events with exenatide BID compared to the control group [37]. These results statistically excluded a 1.8-fold increase of the $\mathrm{CV}$ risk by exenatide and were consistent with the FDA guideline that state that the upper limit of a 2-sided $95 \%$ CI for new diabetes therapies should be $<1.8$. In fact, the results suggest that exenatide treatment may improve $\mathrm{CV}$ outcomes, although this effect failed to reach statistical significance. Our results are consistent with those of a recent retrospective analysis of a large insurance database in which the 39,275 patients treated with exenatide twice daily were found to be significantly less likely to have a CV event than were the 381,218 patients treated with other glucose-lowering therapies (HR 0.81, 95\% CI 0.68-0.91, $P=0.01$ ) [42]. Although the results of the current meta-analysis suggest that there may be an association between exenatide and improved CV outcomes, data from multi-year, randomized, controlled, adequately-powered clinical trials with prospective blinded adjudication of $\mathrm{CV}$ events are

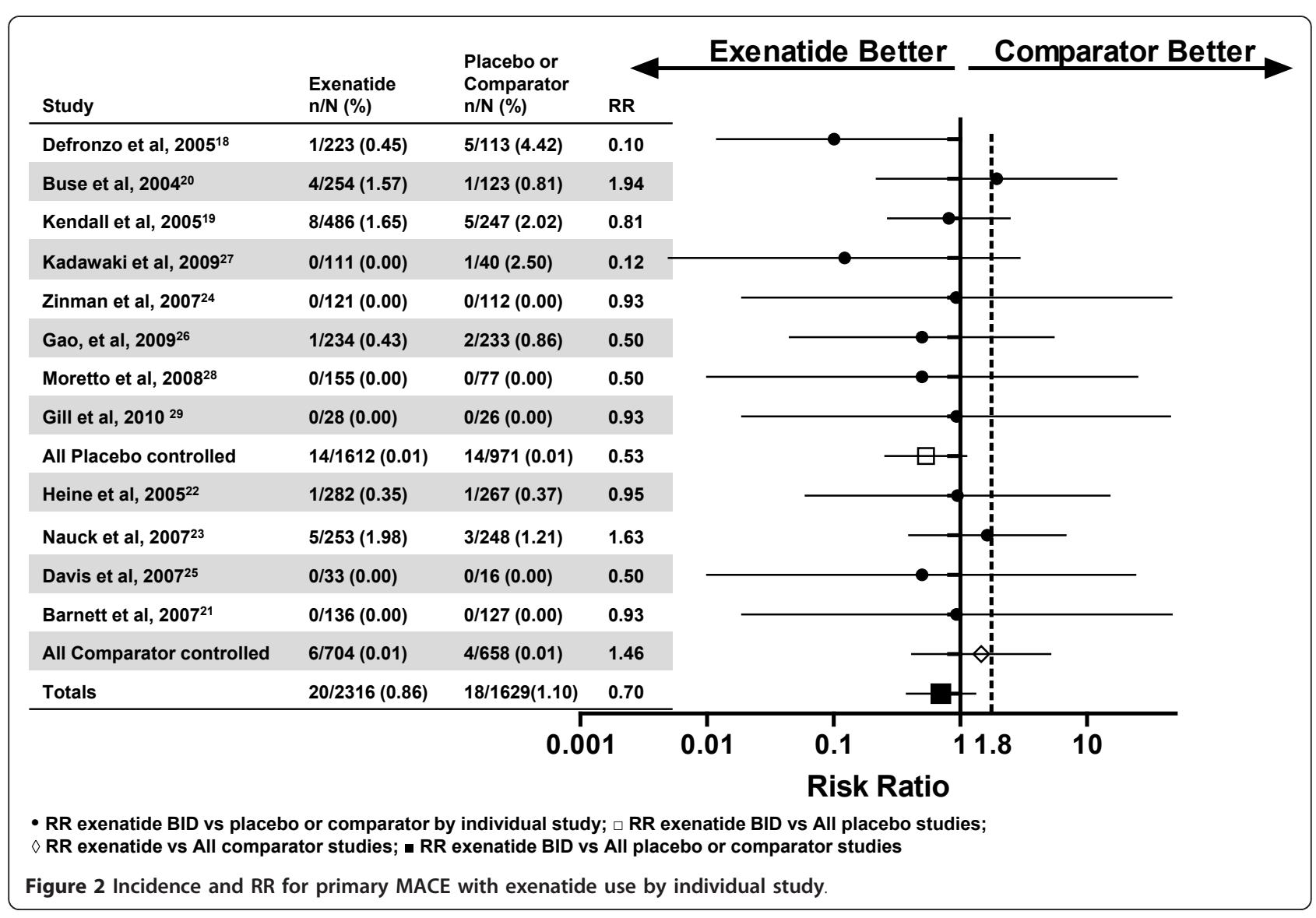




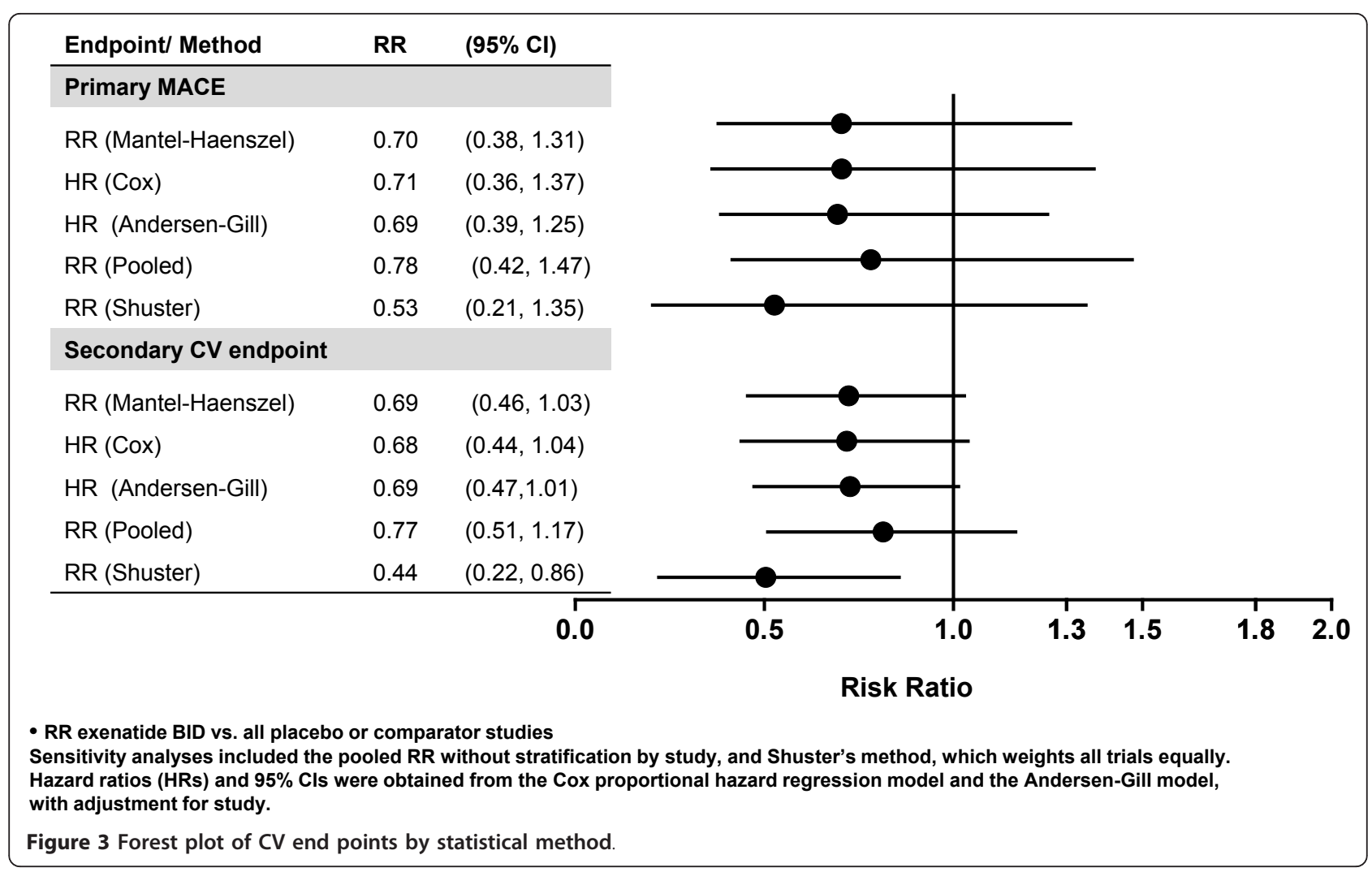

needed to evaluate whether exenatide has cardio-protective effects.

Despite the increased relative risk of $\mathrm{CV}$ disease in diabetes, the absolute risk may only be reduced when multifactorial treatment strategies are used [43-45]; therefore, the CV risk associated with glucose-lowering agents is not easily ascertained. Even in randomized, controlled trials that included $\mathrm{CV}$ outcomes as part of the endpoint, the outcomes may be difficult to interpret.

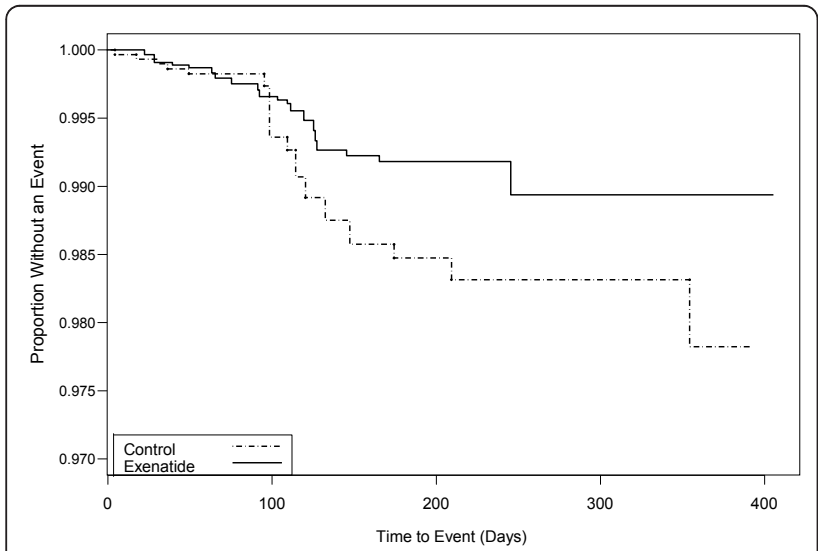

Figure 4 Weighted Kaplan Meier plot for subjects without a primary MACE event by treatment in controlled studies of exenatide BID.
The University Group Diabetes Program (UGDP) suggested treatment with tolbutamide, a first generation SFU, was associated with increased risk of negative CV outcomes [46]. Despite the limitations of UGDP, the implication that SFUs were associated with some risk remained until the results of the landmark UKPDS were available [47]. From UKPDS, it was evident that SFU or MET monotherapy was associated with reduced CV risk; however, treatment with the combination of SFU and MET was associated with increased CV risk [48]. Demonstration of the impact of glycemic control on the risk of acute MI was limited by the relatively low absolute MI event rate, but long-term follow-up studies of UKPDS and DCCT found that intense glycemic control reduced major CV events $[31,49,50]$.

Four large trials have analyzed the effects of glucose lowering on CV risk [30,31,35,47,49,51]. The UKPDS studied patients early in the course of disease and found that intensive therapy was associated with a reduction in $\mathrm{CV}$ events, especially in the small cohort of obese patients who were treated with metformin $[47,49]$. The 3 large trials (ADVANCE, ACCORD, and VADT) in patients with longer duration of disease generally had HRs less than 1.0 with intensive therapy, but none achieved statistical significance $[30,35,51]$. The systematic review of these 4 trials in a pooled analysis did show a reduction in CV disease (RR 0.90, 95\% CI 
0.83-0.98) and coronary heart disease (RR 0.89, 95\% CI 0.81-0.96), but not in stroke, coronary heart failure, $\mathrm{CV}$ disease mortality, or all-cause mortality [52]. ACCORD and VADT reported that mortality was associated with hypoglycemia $[35,51,53]$. In fact, ACCORD was discontinued because of this increased mortality. Hypoglycemia in each of the arms of the ACCORD trial was associated with increased mortality, though hypoglycemia did not explain the increased mortality risk in the intensive arm [53]. Recently, lower $\mathrm{HbA}_{1 \mathrm{C}}$ values in the intensive arm were reported to be associated with reduced $\mathrm{CV}$ disease events [54] and difficulty in lowering $\mathrm{HbA}_{1 \mathrm{C}}$ below $7 \%$ in the intensive group may actually have been the best predictor of $\mathrm{CV}$ events [54]. None of the trials in patients with longer duration of disease demonstrated a clear adverse (or beneficial) effect of any particular glucose-lowering medication, although the trials were not designed to answer this question. However, a reasonable interpretation is that there may be small to modest benefits on $\mathrm{CV}$ disease events with glucose lowering as long as such glucose lowering can be achieved without increased risk for hypoglycemia. In addition, the difficulty in understanding the results of the recent $\mathrm{CV}$ trials may be due, in part, to the declining incidence rate of CV events in patients with diabetes. The declining event rates observed in the most recent $\mathrm{CV}$ studies may suggest that improvements to $\mathrm{CV}$ risk may be due to other temporal phenomena. Resolving the problem of residual risk is increasingly difficult to prove experimentally because the low absolute risk of an event requires large numbers of subjects to be followed for a long period of time with a disease that progresses and requires evolving therapeutic intervention.

\section{Potential CV Effects of GLP-1 Receptor Agonists}

Potential mechanisms of CV disease protection by GLP1 in humans have been proposed but not established. One possibility is glycemic control, given the positive correlation between $\mathrm{HbA}_{1 \mathrm{C}}$ and $\mathrm{CV}$ events $[55,56]$. Another possibility is the association of GLP-1 receptor agonist treatment with weight stability or reduction. Although the effects of weight gain in treated patients with type 2 diabetes have not been thoroughly investigated, an observational study showed that $\mathrm{CV}$ disease risk in patients with type 2 diabetes increased with increasing BMI [57]. Although the majority of patients with type 2 diabetes are overweight and at greater risk of $\mathrm{CV}$ disease than are patients without type 2 diabetes [58], most conventional diabetes medications are weight neutral or induce weight gain $[59,60]$.

Improving glycemic control, supporting weight loss, and minimizing hypoglycemia are the clinical priorities in the management of most patients with type 2 diabetes [61]. During the last decade, exenatide BID therapy has been consistently associated with improvements in glycemic control coupled with weight loss in clinical and observational studies of patients with type 2 diabetes [62,63]. Importantly, exenatide therapy does not increase the risk of severe hypoglycemia when used in the absence of agents commonly associated with hypoglycemia, primarily SFU and insulin. In several small studies, insulin-induced hypoglycemia was associated with lengthened QT intervals, which may increase the risk of arrhythmia $[64,65]$. It is possible that the low risk of hypoglycemia with GLP-1 receptor agonist treatments may contribute to a lower risk of CV events.

Exenatide therapy has been associated with reductions in multiple cardiovascular risk factors. A pooled analysis of randomized controlled clinical trials of exenatide BID demonstrated a significant reduction in systolic blood pressure with exenatide therapy compared with placebo or insulin therapy [66]; a similar result was obtained in a recent randomized controlled clinical trial [67]. In open-label extension studies lasting up to 3 years, exenatide BID treatment resulted in improved glycemic control accompanied by moderate weight loss and improvements in BP, cholesterol levels, inflammatory markers, and insulin resistance for some patients [15-17]. Improvements in postprandial lipidemia associated with exenatide treatment were identified in a 1 -year open-label study that compared the efficacies of exenatide and insulin glargine $[68,69]$. Compared with insulin-treatment, significant decreases in post-prandial triglycerides, free fatty acids, HDL-C, VLDL-C, and Apo B48 were observed with exenatide treatment. No between-group differences were found in postprandial total cholesterol, LDL-C, ApoA1, ApoA2, Apo B100, or ApoC3, although exenatide reduced the post-prandial oxidative stress markers P-malondialdehyde and oxidized LDL [68]. Reductions in high-sensitivity C-reactive protein and increases in total adiponectin were also observed [69]. The latter changes were not statistically dependent on changes in fat mass or body weight [69].

Exenatide therapy has been associated with 1 or $2 \mathrm{bpm}$ increases in heart rate in individual clinical trials $[29,67]$. In this analysis, mean heart rate changes were $+0.5 \mathrm{bpm}$ for exenatide and $+0.1 \mathrm{bpm}$ for the pooled comparators. The clinical importance of small increases in heart rate is unclear. The majority of epidemiological studies in patients with diabetes have studied the effects of $10 \mathrm{bpm}$ increases in heart rate from any cause, which are associated with increased CV risk [70,71].

No effects of exenatide BID on cardiac repolarization (QT/QTc interval) have been observed in preclinical toxicology studies or during clinical studies of exenatide BID in patients with type 2 diabetes. A thorough QT study in healthy volunteers demonstrated that, 
compared with placebo treatment, exenatide BID treatment was not associated with clinically significant QTc prolongation [72]. A thorough QT study for an investigational, long-acting formulation of exenatide is ongoing.

Extrapolating from pre-clinical studies, it is possible that GLP-1 receptors located in the heart and vasculature may play a protective role with respect to $\mathrm{CV}$ disease [73,74]. In animal models, GLP-1 reduced infarct size after coronary artery ischemia [75], improved left ventricular ejection volume in heart failure [73], improved glucose uptake in the myocardium [74], and induced nitric oxide-independent vasorelaxation in the endothelium [74]. Recent studies evaluated treatment with a GLP-1 receptor agonist in rodent models of severe hypertension or congestive heart failure. Dahl salt-sensitive rats fed a high-salt diet were found to have less hypertension, renal dysfunction, and mortality after 4 weeks of continuous therapy with a GLP-1 analog than were those without treatment [76]. Similarly, rats with heart failure after coronary artery ligation that were treated with a GLP-1 analog demonstrated improved cardiac function, cardiac dimension, exercise capacity, and survival compared to untreated rats [77]. In humans, there is limited evidence that GLP-1 improves left ventricular ejection fraction, reperfusion, or functional status in patients with heart failure or MI $[78,79]$. Further studies are warranted in patients with specific types of CV disease to understand if the latter effects and those on the endothelium are seen in humans. Studies of the CV effects of different formulations of GLP-1 receptor agonists, including an oral formulation, are also justified to determine whether similar results are seen in all members of this drug class [80].

\section{Limitations}

Major limitations of this analysis were the inclusion of studies of short duration, lack of complete data on CV history, and the lack of pre-specified and blinded adjudication of the CV events. In addition, the incidence of $\mathrm{CV}$ events was low in the individual trials. As with all meta-analyses, the current meta-analysis was retrospective in nature. Pooling the placebo group with a single active-comparator group is another potential limitation of this analysis. The rationale for pooling the placeboand active-comparator patients was to provide greater power for this analysis by increasing the sample size and the number of observed outcomes.

\section{Conclusions}

On the basis of this integrated analysis of 3,945 participants representing 1,070 patient-years of exenatide exposure and 780 patient-years of PC exposure, no increase in $\mathrm{CV}$ risk was associated with use of exenatide
BID (vs. PC) in patients with type 2 diabetes participating in clinical trials. This analysis, conducted in compliance with FDA guidance on the subject, provides insight into the $\mathrm{CV}$ safety of exenatide treatment.

\section{Acknowledgements and Funding}

We thank Carl Brown for earlier contributions to this analysis and Mary Beth DeYoung and Lee Meller for assistance with final revisions. We also thank Haiying Dong and the Amylin Statistical Programming Group for their contributions to this analysis. CB, MBDY, LM and HD are employees and stockholders of Amylin Pharmaceuticals, Inc. Dawn Nicewarner and Irina Yushmanova, MD were employees of Amylin Pharmaceuticals, Inc. at the time of this analysis.

This analysis was sponsored by Amylin Pharmaceuticals, Inc. and Eli Lilly and Co., which have a global agreement to collaborate on the development and commercialization of exenatide.

\section{Author details}

${ }^{1}$ MedStar Health Research Institute, Hyattsville, MD, USA. ${ }^{2}$ Amylin Pharmaceuticals, Inc., San Diego, CA, USA. ${ }^{3}$ Eli Lilly and Company and LillyUSA, Indianapolis, IN, USA.

\section{Authors' contributions}

RR reviewed and interpreted the data, requested additional analysis, and critically reviewed the manuscript; $J H$ participated in the acquisition and statistical analysis of the data and reviewed the manuscript; DN participated in analysis and interpretation of the data and drafted the manuscript; IY participated in design of the analysis, data interpretation, and critical review of the manuscript; BJH participated in analysis and interpretation of the data, requested additional analysis, and drafted sections of the manuscript; LS contributed to the conception and design of the analysis, interpreted the analyzed data, and critically reviewed the manuscript. All authors read and approved the final manuscript.

\section{Competing interests}

RR has received research support during the last 5 years from Amylin Pharmaceuticals, Inc., Eli Lilly \& Company, NovoNordisk, GSK, Roche, and Sanofi Aventis; he is not an employee or stock-holder of any of these companies and does not have any other financial competing interests. $\mathrm{JH}$, $D N$, IY, and LS were employees and stockholders of Amylin Pharmaceuticals, Inc. at the time of this analysis. BJH is an employee and stockholder of Eli Lilly \& Co. Amylin Pharmaceuticals, Inc. and holds the patent for synthetic Exendin-4 (exenatide).

Received: 5 November 2010 Accepted: 16 March 2011 Published: 16 March 2011

\section{References}

1. Buse JB, Ginsbert HN, Bakris GL, Clark N, Costa F, Eckel R, Fonseca V, Gerstein H, Grundy S, Nesto R, Pignone MP, Plutzky J, Porte D, Redbert R, Stitzel KF, Stone NJ: Primary prevention of cardiovascular diseases in people with diabetes mellitus: a scientific statement from the American Heart Association and the American Diabetes Association. Diabetes Care 2007, 30:162-172.

2. Nissen SE, Wolski K: Effect of rosiglitazone on the risk of myocardial infarction and death from cardiovascular causes. N Engl J Med 2007, 356:2457-2471.

3. Cleland JG, Atkin SL: Thiazolidinediones, deadly sins, surrogates, and elephants. Lancet 2007, 370:1103-1104.

4. Diamond GA, Bax L, Kaul S: Uncertain effects of rosiglitazone on the risk for myocardial infarction and cardiovascular death. Ann Intern Med 2007 147:578-581.

5. Mulrow CD, Cornell J, Localio AR: Rosiglitazone: a thunderstorm from scarce and fragile data. Ann Intern Med 2007, 147:585-587.

6. Psaty BM, Furberg CD: Rosiglitazone and cardiovascular risk. N Engl J Med 2007, 356:2522-2524.

7. Rosen CJ: Revisiting the rosiglitazone story-lessons learned. N Engl J Med 2010, 363:803-806 
8. Home PD, Pocock SJ, Beck-Nielsen H, Curtis PS, Gomis R, Hanefeld M, Jones NP, Komajda M, McMurray JJ: Rosiglitazone evaluated for cardiovascular outcomes in oral agent combination therapy for type 2 diabetes (RECORD): a multicentre, randomised, open-label trial. Lancet 2009, 373:2125-2135.

9. Nissen SE, Wolski K: Rosiglitazone revisited: an updated meta-analysis of risk for myocardial infarction and cardiovascular mortality. Arch Intern Med 2010, 170:1191-1201.

10. Graham DJ, Ouellet-Hellstrom R, MaCurdy TE, Ali F, Sholley C, Worrall C, Kelman JA: Risk of acute myocardial infarction, stroke, heart failure, and death in elderly Medicare patients treated with rosiglitazone or pioglitazone. JAMA 2010, 304:411-418.

11. Nissen SE: Setting the RECORD Straight. JAMA 2010, 303:1194-1195.

12. Juurlink DN: Rosiglitazone and the case for safety over certainty. JAMA 2010, 304:469-471.

13. Drucker DJ, Sherman SI, Gorelick FS, Bergenstal RM, Sherwin RS, Buse JB: Incretin-based therapies for the treatment of type 2 diabetes: evaluation of the risks and benefits. Diabetes Care 2010, 33:428-433.

14. Parks $M$, Rosebraugh $C$ : Weighing risks and benefits of liraglutide-the FDA's review of a new antidiabetic therapy. N Engl J Med 2010, 362:774-777.

15. Blonde L, Klein EJ, Han J, Zhang B, Mac SM, Poon TH, Taylor KL, Trautmann ME, Kim DD, Kendall DM: Interim analysis of the effects of exenatide treatment on $\mathrm{A} 1 \mathrm{C}$, weight and cardiovascular risk factors over 82 weeks in 314 overweight patients with type 2 diabetes. Diabetes Obes Metab 2006, 8:436-447

16. Ratner RE, Maggs $D$, Nielsen LL, Stonehouse AH, Poon T, Zhang B, Bicsak TA, Brodows RG, Kim DD: Long-term effects of exenatide therapy over 82 weeks on glycaemic control and weight in over-weight metformin-treated patients with type 2 diabetes mellitus. Diabetes Obes Metab 2006, 8:419-428.

17. Klonoff DC, Buse JB, Nielsen LL, Guan X, Bowlus CL, Holcombe JH, Wintle ME, Maggs DG: Exenatide effects on diabetes, obesity, cardiovascular risk factors and hepatic biomarkers in patients with type 2 diabetes treated for at least 3 years. Curr Med Res Opin 2008, 24:275-286.

18. Defronzo RA, Ratner RE, Han J, Kim DD, Fineman MS, Baron AD: Effects of exenatide (exendin-4) on glycemic control and weight over 30 weeks in metformin-treated patients with type 2 diabetes. Diabetes Care 2005, 28:1092-1100.

19. Kendall DM, Riddle MC, Rosenstock J, Zhuang D, Kim DD, Fineman MS, Baron AD: Effects of exenatide (exendin-4) on glycemic control over 30 weeks in patients with type 2 diabetes treated with metformin and a sulfonylurea. Diabetes Care 2005, 28:1083-1091.

20. Buse JB, Henry RR, Han J, Kim DD, Fineman MS, Baron AD: Effects of exenatide (exendin-4) on glycemic control over 30 weeks in sulfonylurea-treated patients with type 2 diabetes. Diabetes Care 2004, 27:2628-2635

21. Barnett $A H$, Burger J, Johns D, Brodows R, Kendall DM, Roberts A, Trautmann ME: Tolerability and efficacy of exenatide and titrated insulin glargine in adult patients with type 2 diabetes previously uncontrolled with metformin or a sulfonylurea: A multinational, randomized, openlabel, two-period, crossover noninferiority trial. Clin Ther 2007, 29:2333-2348.

22. Heine RJ, Van Gaal LF, Johns D, Mihm MJ, Widel MH, Brodows RG, Group $\mathrm{ftGS}$ : Exenatide versus insulin glargine in patients with suboptimally controlled type 2 diabetes: a randomized trial. Ann Intern Med 2005, 143:559-569.

23. Nauck MA, Duran S, Kim D, Johns D, Northrup J, Festa A, Brodows B, Trautmann M: A comparison of twice-daily exenatide and biphasic insulin aspart in patients with type 2 diabetes who were suboptimally controlled with sulfonylurea and metformin: a non-inferiority study. Diabetologia 2007, 50:259-267.

24. Zinman B, Hoogwerf BJ, Durán Garcia S, Milton DR, Giaconia JM, Kim DD, Trautmann ME, Brodows RG: The effect of adding exenatide to a thiazolidinedione in suboptimally controlled type 2 diabetes. Ann Intern Med 2007, 146:477-485

25. Davis SN, Johns D, Maggs D, Xu H, Northrup JH, Brodows RG: Exploring the substitution of exenatide for insulin in patients with type 2 diabetes treated with insulin in combination with oral antidiabetes agents. Diabetes Care 2007, 30:2767-2772.
26. Gao Y, Yoon KH, Chuang LM, Mohan V, Ning G, Shah S, Jang HC, Wu TJ, Johns D, Northrup J, Brodows R: Efficacy and safety of exenatide in patients of Asian descent with type 2 diabetes inadequately controlled with metformin or metformin and a sulphonylurea. Diabetes Res Clin Pract 2009, 83:69-76.

27. Kadowaki T, Namba M, Yamamura A, Sowa H, Wolka AM, Brodows RG: Exenatide exhibits dose-dependent effects on glycemic control over 12 weeks in Japanese patients with suboptimally controlled type 2 diabetes. Endocr J 2009, 56:415-424.

28. Moretto TJ, Milton DR, Ridge TD, MacConell LA, Okerson T, Wolka AM, Brodows RG: Efficacy and tolerability of exenatide monotherapy over 24 weeks in antidiabetic drug-naive patients with type 2 diabetes: a randomized, double-blind, placebo-controlled, parallel-group study. Clin Ther 2008, 30:1448-1460.

29. Gill A, Hoogwerf BJ, Burger J, Bruce S, Macconell L, Yan P, Braun D, Giaconia J, Malone J: Effect of exenatide on heart rate and blood pressure in subjects with type 2 diabetes mellitus: a double-blind, placebo-controlled, randomized pilot study. Cardiovasc Diabetol 2010, 9:6.

30. ADVANCE Collaborative Group: Intensive blood glucose control and vascular outcomes in patients with type 2 diabetes. New Engl J Med 2008, 358:2560-2572

31. UK Prospective Diabetes Study Group: Intensive blood-glucose control with sulphonylureas or insulin compared with conventional treatment and risk of complications in patients with type 2 diabetes (UKPDS 33). Lancet 1998, 352:837-853.

32. Davis BR, Cutler JA, Gordon DJ, Furberg CD, Wright JT Jr, Cushman WC, Grimm RH, LaRosa J, Whelton PK, Perry HM, Alderman MH, Ford CE, Oparil S, Francis C, Proschan M, Pressel S, Black HR, Hawkins CM: Rationale and design for the Antihypertensive and Lipid Lowering Treatment to Prevent Heart Attack Trial (ALLHAT). ALLHAT Research Group. Am J Hypertens 1996, 9:342-360.

33. Farmer JA, Gotto AM Jr: The Heart Protection Study: expanding the boundaries for high-risk coronary disease prevention. Am J Cardiol 2003, 92:3i-9i.

34. Scandinavian Simvastatin Study Group: Randomised trial of cholesterol lowering in $\mathbf{4 4 4 4}$ patients with coronary heart disease: the Scandinavian Simvastatin Survival Study (4S). Lancet 1994, 344:1383-1389.

35. ACCORD Study Group: Effects of intensive glucose lowering in type 2 diabetes. N Engl J Med 2008, 358:2545-2559.

36. Food and Drug Administration: Official transcript Endocrinologic and Metabolic Drugs Advisory Committee meeting, April 1, 2009. Silver Spring, MD; 2009 [http://www.fda.gov/downloads/AdvisoryCommittees/ CommitteesMeetingMaterials/Drugs/

EndocrinologicandMetabolicDrugsAdvisoryCommittee/UCM151169.pdf], updated 02/17/2010.

37. Food and Drug Administration: Guidance for industry: diabetes mellitusevaluating cardiovascular risk in new antidiabetic therapies to treat type 2 diabetes. Silver Spring, MD; 2008 [http://www.fda.gov/downloads/Drugs/ GuidanceComplianceRegulatorylnformation/Guidances/ucm071627.pdf], cited 2009 August 27.

38. Shuster JJ, Jones LS, Salmon DA: Fixed vs random effects meta-analysis in rare event studies: the rosiglitazone link with myocardial infarction and cardiac death. Stat Med 2007, 26:4375-4385

39. Amato DJ: A generalized Kaplan-Meier estimator for heterogeneous population. Commun Stat Theory 1988, 17:263-286

40. UIm K: Simple method to calculate the confidence interval of a standardized mortality ratio (SMR). Am J Epidemiol 1990, 131:373-375.

41. Ng HKT, Tang ML: Testing the equality of two Poisson means using the rate ratio. Stat Med 2005, 24:955-965.

42. Best JH, Hoogwerf BJ, Herman WH, Pelletier EM, Smith DB, Wenten M, Hussein MA: Risk of cardiovascular disease events in patients with type 2 diabetes prescribed the glucagon-like peptide 1 (GLP-1) receptor agonist exenatide twice daily or other glucose-lowering therapies: a retrospective analysis of the LiveLink database. Diabetes Care 2011, 34:90-95.

43. UK Prospective Diabetes Study Group: Tight blood pressure control and risk of macrovascular and microvascular complications in type 2 diabetes: UKPDS 38. BMJ 1998, 317:703-713.

44. UK Prospective Diabetes Study Group: Efficacy of atenolol and captopril in reducing risk of macrovascular and microvascular complications in type 2 diabetes: UKPDS 39. BMJ 1998, 317:713-720. 
45. Gaede P, Lund-Andersen H, Parving HH, Pedersen O: Effect of a multifactorial intervention on mortality in type 2 diabetes. $N$ Engl J Med 2008, 358:580-591.

46. Schwartz TB, Meinert CL: The UGDP controversy: thirty-four years of contentious ambiguity laid to rest. Perspect Biol Med 2004, 47:564-574.

47. UK Prospective Diabetes Study Group: Effect of intensive blood-glucose control with metformin on complications in overweight patients with type 2 diabetes (UKPDS 34). Lancet 1998, 352:854-865.

48. Nathan DM, Cleary PA, Backlund JY, Genuth SM, Lachin JM, Orchard TJ, Raskin P, Zinman B: Intensive diabetes treatment and cardiovascular disease in patients with type 1 diabetes. N Engl J Med 2005, 353:2643-2653

49. Holman RR, Paul SK, Bethel AM, Matthews DR, Neil HAW: 10-Year follow-up of intensive glucose control in type 2 diabetes. N Engl J Med 2008, 359:1577-1589.

50. Diabetes Control and Complications Trial Research Group: The effect of intensive treatment of diabetes on the development and progression of long-term complications in insulin-dependent diabetes mellitus. $N$ Engl J Med 1993, 329:977-986.

51. Duckworth W, Abraira C, Moritz T, Reda D, Emanuele N, Reaven PD, Zieve FJ, Marks J, Davis SN, Hayward R, Warren SR, Goldman S, McCarren M, Vitek ME, Henderson WG, Huang GD, Investigators ftV: Glucose control and vascular complications in veterans with type 2 diabetes. New Engl J Med 2009, 360:129-139

52. Kelly TN, Bazzano LA, Fonseca VA, Thethi TK, Reynolds K, He J: Systematic review: glucose control and cardiovascular disease in type 2 diabetes. Ann Intern Med 2009, 151:394-403.

53. Bonds DE, Miller ME, Bergenstal RM, Buse JB, Byington RP, Cutler JA, Dudl RJ, Ismail-Beigi F, Kimel AR, Hoogwerf B, Horowitz KR, Savage PJ, Seaquist ER, Simmons DL, Sivitz WI, Speril-Hillen JM, Sweeney ME: The association between symptomatic, severe hypoglycaemia and mortality in type 2 diabetes: retrospective epidemiological analysis of the ACCORD study. BMJ 2010, 340:b4909

54. Riddle MC, Ambrosius WT, Brillon DJ, Buse JB, Byington RP, Cohen RM, Goff DCJ, Malozowski S, Margolis KL, Probstfield JL, Schnall A, Seaquist ER: Epidemiologic relationships between $\mathrm{A} 1 \mathrm{C}$ and all-cause mortality during a median 3.4-year follow-up of glycemic treatment in the ACCORD trial. Diabetes Care 2010, 33:983-990.

55. Stratton IM, Adler Al, Neil HA, Matthews DR, Manley SE, Cull CA, Hadden D, Turner RC, Holman RR: Association of glycaemia with macrovascular and microvascular complications of type 2 diabetes (UKPDS 35): prospective observational study. BMJ 2000, 321:405-412

56. Selvin E, Marinopoulos S, Berkenblit G, Rami T, Brancati FL, Powe NR, Golden SH: Meta-analysis: glycosylated hemoglobin and cardiovascular disease in diabetes mellitus. Ann Intern Med 2004, 141:421-431.

57. Eeg-Olofsson K, Cederholm J, Nilsson PM, Zethelius B, Nunez L, Gudbjörnsdóttir S, Eliasson B: Risk of cardiovascular disease and mortality in overweight and obese patients with type 2 diabetes: an observational study in 13,087 patients. Diabetologia 2009, 52:65-73.

58. Maggio CA, Pi-Sunyer FX: The prevention and treatment of obesity. Application to type 2 diabetes. Diabetes Care 1997, 20:1744-1766.

59. Nathan DM, Buse JB, Davidson MB, Ferrannini E, Holman RR, Sherwin R, Zinman B: Management of hyperglycemia in type 2 diabetes: a consensus algorithm for the initiation and adjustment of therapy: update regarding thiazolidinediones: a consensus statement from the American Diabetes Association and the European Association for the Study of Diabetes. Diabetes Care 2008, 31:173-175.

60. Mitri J, Hamdy O: Diabetes medications and body weight. Expert Opin Drug Saf 2009, 8:573-584.

61. Rodbard HW, Jellinger PS, Davidson JA, Einhorn D, Garber AJ, Grunberger G, Handelsman Y, Horton ES, Lebovitz H, Levy P, Moghissi ES, Schwartz SS: Statement by an American Association of Clinical Endocrinologists/ American College of Endocrinology consensus panel on type 2 diabetes mellitus: an algorithm for glycemic control. Endocr Pract 2009, 15:540-559.

62. Gallwitz B: Benefit-risk assessment of exenatide in the therapy of type 2 diabetes mellitus. Drug Safety 2010, 33:87-100.

63. Buysschaert M, Preumont V, Oriot PR, Paris I, Ponchon M, Scarnière D, Selvais $P$, Exenatide ftUSGf: One-year metabolic outcomes in patients with type 2 diabetes treated with exenatide in routine practice. [French]. Diabetes Metab 2010, 36:381-388.
64. Landstedt-Hallin L, Englund A, Adamson U, Lins PE: Increased QT dispersion during hypoglycaemia in patients with type 2 diabetes mellitus. J Intern Med 1999, 246:299-307.

65. Marques JL, George E, Peacey SR, Harris ND, Macdonald IA, Cochrane T, Heller SR: Altered ventricular repolarization during hypoglycaemia in patients with diabetes. Diabet Med 1997, 14:648-654.

66. Okerson T, Yan P, Stonehouse A, Brodows R: Effects of exenatide on systolic blood pressure in subjects with type 2 diabetes. Am J Hypertens 2010, 23:334-339.

67. Buse JB, Rosenstock J, Sesti G, Schmidt WE, Montanya E, Brett JH, Zychma M, Blonde L: Liraglutide once a day versus exenatide twice a day for type 2 diabetes: a 26-week randomised, parallel-group, multinational, open-label trial (LEAD-6). Lancet 2009, 374:39-47.

68. Bunck MC, Cornér A, Eliasson B, Heine RJ, Shaginian RM, Wu Y, Yan P, Smith U, Yki-Järvinen $H$, Diamant M, Taskinen MR: One-year treatment with exenatide vs. Insulin Glargine: Effects on postprandial glycemia, lipid profiles, and oxidative stress. Atherosclerosis 2010, 212:223-229.

69. Bunck MC, Diamant M, Eliasson B, Cornér A, Shaginian RM, Heine RJ Taskinen MR, Yki-Järvinen $\mathrm{H}$, Smith U: Exenatide affects circulating cardiovascular risk biomarkers independently of changes in body composition. Diabetes Care 2010, 33:1734-1737.

70. Anselmino M, Öhrvik J, Rydén L: Resting heart rate in patients with stable coronary artery disease and diabetes: a report from the euro heart survey on diabetes and the heart. Eur Heart J 2010, 31:3040-3045.

71. Stettler C, Bearth A, Allemann S, Zwahlen M, Zanchin L, Deplazes M Christ ER, Teuscher A, Diem P: $\mathrm{QT}_{\mathrm{c}}$ interval and resting heart rate as longterm predictors of mortality in type 1 and type 2 diabetes mellitus: a 23-year follow-up. Diabetologia 2007, 50:186-194.

72. Linnebjerg $H$, Seger M, Kothare P, Hunt T, Hons B, Mitchell Ml: The effect of exenatide on QTc interval in healthy subjects [abstract]. Diabetes 2009, 58:A161.

73. Nikolaidis LA, Elahi D, Hentosz T, Doverspike A, Huerbin R, Zourelias L, Stolarski C, Shen YT, Shannon RP: Recombinant glucagon-like peptide-1 increases myocardial glucose uptake and improves left ventricular performance in conscious dogs with pacing-induced dilated cardiomyopathy. Circulation 2004, 110:955-961.

74. Zhao T, Parikh P, Bhashyam S, Bolukoglu H, Poornima I, Shen Y, Shannon R: Direct effects of glucagon-like peptide- 1 on myocardial contractility and glucose uptake in normal and postischemic isolated rat hearts. $J$ Pharmacol Exp Ther 2006, 317:1106-1113.

75. Bose AK, Mocanu MM, Carr RD, Brand CL, Yellon DM: Glucagon-like peptide 1 can directly protect the heart against ischemia/reperfusion injury. Diabetes 2005, 54:146-151.

76. Liu Q, Adams L, Broyde A, Fernandez R, Baron AD, Parkes DG, Liu Q, Adams L, Broyde A, Fernandez R, Baron AD, Parkes DG: The exenatide analogue $A C 3174$ attenuates hypertension, insulin resistance, and renal dysfunction in Dahl salt-sensitive rats. Cardiovasc Diabetol 2010, 9:32.

77. Liu Q, Anderson C, Broyde A, Polizzi C, Fernandez R, Baron A, Parkes DG: Glucagon-like peptide- 1 and the exenatide analogue AC3174 improve cardiac function, cardiac remodeling, and survival in rats with chronic heart failure. Cardiovasc Diabetol 2010, 9:76.

78. Nikolaidis LA, Mankad S, Sokos GG, Miske G, Shah A, Elahi D, Shannon RP: Effects of glucagon-like peptide- 1 in patients with acute myocardial infarction and left ventricular dysfunction after successful reperfusion. Circulation 2004, 109:962-965.

79. Sokos GG, Nikolaidis LA, Mankad S, Elahi D, Shannon RP: Glucagon-like peptide-1 infusion improves left ventricular ejection fraction and functional status in patients with chronic heart failure. J Card Fail 2006, 12:694-699.

80. Eldor R, Kidron M, Greenberg-Shushlav $Y$, Arbit E: Novel glucagon-like peptide-1 analog delivered orally reduces postprandial glucose excursions in porcine and canine models. J Diabetes Sci Technol 2010, 4:1516-1523.

doi:10.1186/1475-2840-10-22

Cite this article as: Ratner et al:: Cardiovascular safety of exenatide BID: an integrated analysis from controlled clinical trials in participants with type 2 diabetes. Cardiovascular Diabetology 2011 10:22. 